\title{
Personal ECG Devices: How Will Healthcare Systems Cope? A Single Centre Case Study
}

\author{
Rob Brisk ${ }^{1}$, Raymond Bond ${ }^{2}$, Dewar Finlay ${ }^{3}$, David McEneaney $^{1}$ \\ ${ }^{1}$ Department of cardiology, Craigavon Area Hospital, Portadown, Northern Ireland \\ ${ }^{2}$ School of Computing, Ulster University, Jordanstown, Northern Ireland \\ ${ }^{2}$ Nanotechnology and Integrated Bioengineering Centre, Ulster University, Jordanstown, Northern Ireland
}

\begin{abstract}
The uptake of personal ECG devices is poised to explode in coming years. This review considers the potential impact of this on the cardiology department of an NHS teaching trust in the UK. The authors conclude that such devices may substantially increase the workload of a service already under significant pressure, with unclear benefit to patients. Potential solutions to this issue include novel algorithms (perhaps deep learning) to minimize false positive results.
\end{abstract}

\section{Introduction}

With the prevalence of personal ECG devices already on the rise and the Apple Watch Series 4 recently hitting the market, the number of daily ECG recordings in the developed world is poised to explode. [1] While some individuals will undoubtedly benefit from enhanced diagnosis of cardiac arrhythmias, the consequences of false alarms are likely to be detrimental to patients and clinicians alike. This article aims to describe the possible impact of this technology on a typical cardiology department of a UK National Health Service (NHS) trust.

\subsection{The clinical setting}

The NHS is the largest single-payer healthcare system, the fifth largest employer globally (after the US Department of Defense, the Chinese People's Liberation Army, Wallmart and MacDonald's) and is responsible for a population of approximately 66 million [2,3]. For this reason, it is often considered to be a particularly good test bed for emerging healthcare technologies. [4]

The Southern Health and Social Care Trust (SHSCT) is an NHS trust in Northern Ireland. The population of the SHSCT's catchment area is approximately 360,000, which has grown substantially over the last decade. [5] The Northern Irish population is ageing more rapidly, scores lower on socioeconomic metrics and has a lower average life expectancy than the rest of the UK. $[6,7,8,9]$ Waiting times for outpatient consultations are correspondingly longer than the national average. [10]

The cardiology department of the SHSCT runs a coronary care unit at each of two teaching hospitals, with six and eight beds respectively. There are an additional 25 permanent inpatient cardiology beds at the larger of the two hospitals, along with two interventional cardiac catheterisation laboratories. The department records about 55,000 inpatient episodes yearly and has a high volume of outpatient encounters (internal statistics).

\subsection{Current ambulatory ECG service}

At present, Holter monitors and cardiac event recorders can be requested directly by physicians outside the cardiology department, including general practitioners (GPs). Implantable loop recorders (ILRs) are only requested by members of the cardiology team and must be approved by a consultant prior to implantation.

Recordings from wearable devices are automatically annotated by specialized software (Sentinel, Spacelabs Healthcare, Snoqualmie, WA, US) and reviewed by one of 13 full time equivalent cardiac physiologists (CPs). Approximately 2,500 studies are undertaken and reported annually. According to SHSCT CPs, reporting a single study takes between 15 minutes and several hours.

The responsibility for acting upon the report generated by a wearable ECG monitor lies with the requesting consultant. No study is undertaken without a responsible consultant physician designated on the request form.

\section{Personal ECG devices}

In their 2018 review, Banshal and Joshi identified 15 widely available personal ECG devices, but only six that were associated with Pubmed-listed studies. [11] Three of these are currently intended for prescription by medical professionals and three are available to individual consumers online. Table 1 shows representative prices for the commercially available devices, with the addition of the Apple Series 4 Watch (not included in the 2018 review as it had not been released).

This review will focus primarily on the impact of two devices: the AliveCor Mobile device and the Apple smartwatch.

\subsection{Characteristics of selected devices}


The AliveCor device is chosen as both the most affordable of the peer reviewed devices and the best supported by published evidence. It has been reviewed favourably by the National Institute for Clinical Excellence (NICE), who noted that the sensitivity and specificity for the automated detection of atrial fibrillation (AF) has been reported in multiple studies as above $85 \%$ and $90 \%$, respectively. [12]

The ECG-enabled Apple Series 4 Watch is chosen for having, by far, the highest predicted sales figures. In 2018, prior to the introduction of ECG capabilities, Apple is estimated to have shipped 22.5 million watches globally. [13] It is not clear how many of the Series 4 watches have been bought in the UK since it went on sale in September 2018, nor how many owners use the ECG technology. However, the authors of this study consider these sales figures to be the most compelling reason to begin thinking about the logistics of the widespread use of self-prescribed ECG monitoring.

\begin{tabular}{lll}
\hline Device & Cost & Outlet \\
\hline Omron Heart Scan & $£ 699.99$ & Amazon.co.uk \\
AliveCor Mobile & $£ 99$ & AliveCor.com \\
REKA Health & N/A & \\
Zenicor ECG & N/A & \\
Schiller MINISCOPE & $£ 1134$ & EKGshop.com \\
ZioPatch & N/A & \\
Apple Series 4 Watch & $£ 389$ & John Lewis \\
\hline
\end{tabular}

Table 1. Representative costs of personal ECG devices.

According to a press release by Apple, the sensitivity and specificity for the automated detection of atrial fibrillation (AF) is $98.3 \%$ and $99.6 \%$, respectively. [14] The study from which these figures were obtained has not yet been published in a peer reviewed journal. The authors consider that there is currently insufficient evidence to support a significant difference in device performance between the Apple Watch and the AliveCor device, and will assume parity henceforth.

At present, both AliveCor and Apple aim to automatically diagnose normal sinus rhythm (NSR) and AF. Other classifications are tachycardia, bradycardia or inconclusive / unreadable. Diagnoses of such traces must be made manually. To this end, both devices can store ECG tracings in PDF format for transmission to the patient's clinician.

AliveCor offers US customers a free manual analysis of their first ECG trace by a cardiologist, and analysis of future recordings for a fee.

ECG recordings are single-lead and must be userinitiated on both devices. On the Apple Watch, users touch a finger to the digital crown of the watch. On the AliveCor device, users place a finger from each hand on the electrodes. Recordings on the Apple device last 30 seconds. Recordings on the AliveCor device last 40 seconds. $[15,16]$

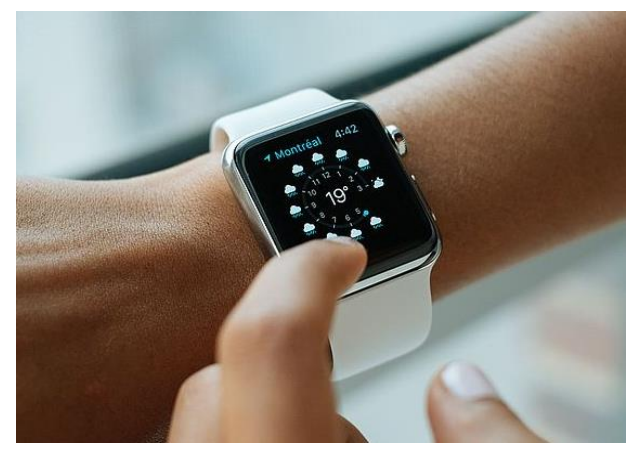

Figure 1. An Apple Watch. The Series 4 model is ECG capable.

\section{Pathway for abnormal recordings}

If either Apple or AliveCor applications detect rhythms other than NSR, both companies return responsibility to the user by suggesting they consult a physician. It is at the point where a UK user sends ECG data to a physician that problems may begin arise from a healthcare provider's perspective. Within the NHS, self-referral to a specialist is only possible under exceptional circumstances (for example, one may see an ophthalmologist directly in eye casualty) or via a private clinic for a fee. In general, however, a patient's first point of contact is their GP or an emergency department (ED) physician. For personal ECGs, it is likely be the former.

At present, there appears to be significant variation in how comfortable GPs are with ECG interpretation. In the experience of the SHSCT cardiology department, some referrals from the community arrive with accurate interpretation of even relatively rare ECG abnormalities (e.g. "?Brugada"), whereas others include fundamental mistakes such as confusing sinus arrhythmia for AF due to irregular R-R intervals but in the presence of clear $\mathrm{P}$ waves.

Regardless of individual competence, however, there can be little doubt that primary care is under unprecedented pressure and that GPs are unlikely to relish the prospect of an additional source of work. [17] It is anticipated by the authors, therefore, that most personal ECG recordings submitted to GPs will be referred to the cardiology department for review.

\subsection{Impact on cardiology services}

In the SHSCT, the current wait for a routine Holter monitor is around 52 weeks (internal statistic). However, all studies are currently ordered by a qualified clinician who, if they deem the test to be urgent, can stipulate a shorter time frame. In the absence of any clear way to triage personal recordings, it seems likely that ECGs mandated directly by patients will be considered a lower priority than studies ordered by qualified medical professionals. It is therefore likely that they will be associated with a substantial delay in reporting. This would 
put some patients at risk, particularly if they have declined to seek expert attention via established channels as a consequence of having submitted potentially diagnostic information.

Furthermore, if the uptake of personal ECG monitoring among SHSCT patients is significant, the extra workload could cause delays across the $\mathrm{CP}$ service. This includes all ambulatory ECG monitoring, pacemaker checks, exercise stress testing, echocardiography services and all cath lab sessions.

Let it be assumed that, two years from now, the entire Apple smartwatch range is ECG capable and continues to sell at 22.5 million units per year. If we disregard a likely preponderance of sales towards industrialised nations like the UK and instead assume an even global sales distribution among 7 billion people, approximately 1000 watches would be acquired by the SHSCT population.

Selder et al. (2019) found that patients using the AliveCor Kardia Mobile device submitted a median of 28 ECGs per patient per year, though this was among patients presenting to cardiology services with palpitations and is likely to be higher than a non-selected population. [18] Indeed, $19 \%$ of ECGs submitted showed AF, whereas AF prevalence among under $65 \mathrm{~s}$ in the general population (the demographic into which the majority of Apple Watch owners fall) is around $2 \%$. [19,20]

Nonetheless, $20 \%$ of all ECGs submitted were flagged as potentially abnormal by the device software and subsequently found to either show NSR or be unclassifiable. A press release from Stanford University regarding the Apple Heart Study noted that a little over half of users receiving an abnormal pulse warning sought medical attention. [21] If there was a similar false positive rate among Apple Watch owners, and if 50\% decided to seek medical review of these recordings, this could result in 2,800 additional ECGs being analysed by SHSCT staff per year: a $100 \%$ increase in outpatient studies analysed.

\subsection{Benefit to patients}

Halcox et al. (2017) report AF diagnosis rates among over $65 \mathrm{~s}$ undergoing routine care (RC) vs twice-weekly ECG monitoring with the AliveCor device. 5 patients receiving $\mathrm{RC}$ were diagnosed with $\mathrm{AF}$ over the course of a year, compared with 19 in the AliveCor group (hazard ratio 3.9, $\mathrm{p}=0.007)$. [22] They were unable to demonstrate a statistically significant difference in rates of cerebrovascular events over the 12-month study, but Boriani et al. (2014) previously concluded that silent AF is associated with a modifiable risk of embolic stroke if anticoagulants are appropriately prescribed. [23] Though the duration of $\mathrm{AF}$ warranting anticoagulation remains a matter of debate, it seems reasonable to conclude that higher rates of $\mathrm{AF}$ and appropriate anticoagulant prescription may be associated with lower rates of embolic stroke.
However, the authors note that the population prevalence of AF among Halcox's over 65 subjects is $9 \%$, compared with $2 \%$ among most Apple Watch owners. [20] Furthermore, the rate of embolic stroke among otherwise well, young patients diagnosed with $\mathrm{AF}$ on routine screening is unknown (Boriani studied patients with preexisting cardiac conditions). There is, therefore, insufficient data to estimate the cost per quality adjusted life year (QALY) of personal ECG monitoring, nor to quantify the impact of high false positive rates on the wider cardiology service and the psychological wellbeing of patients. The authors feel that it is not clear that the widespread uptake of personal ECG devices will benefit patients in the SHSCT.

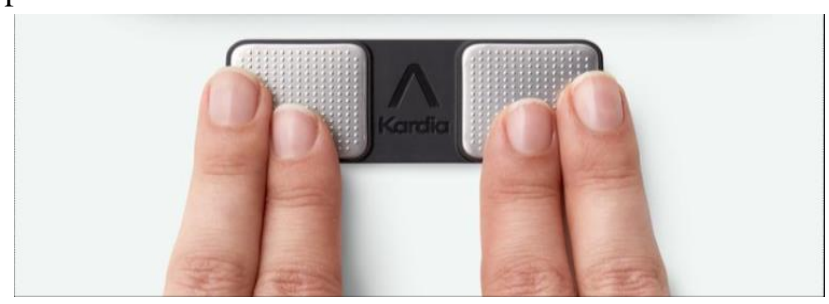

Figure 2. Thr AliveCor Kardia Mobile device.

\section{A technological solution to a technological problem?}

As a final note, recent developments in deep learningbased arrhythmia detection may prove timely in light of the issues discussed in this review. Hannun et al. (2019) claim to have achieved "cardiologist-level" using a 34-layer convolutional neural network trained on large scale ambulatory ECG data. [24] This is a relatively nascent technology but if the results reported in this paper are reproducible by other groups, this may substantially reduce the number of false positive results and shift the riskbenefit balance in favour of personal ECG devices.

\section{Acknowledgments}

This research is supported by the European Union's INTERREG VA Programme, managed by the Special EU Programmes Body (SEUPB), and by the Craigavon Cardiac Care Association.

\section{References}

[1] G.D. Giebel and C. Gissel. "Accuracy of mHealth Devices for Atrial Fibrillation Screening: Systematic Review." JMIR Mhealth Uhealth, vol. 7, no. 6, e13641, Jun 2019.

[2] "The NHS is the world's fifth largest employer," The Nuffield Trust. October 2017. Report available at https://www.nuffieldtrust.org.uk/chart/the-nhs-is-the-worlds-fifth-largest-employer, last accessed $28^{\text {th }}$ August 2019.

[3] "Population estimates," The Office for National Statistics. June 2019. Report available at https://www.ons.gov.uk/peoplepopulationandcommunity/p 
opulationandmigration/populationestimates, last accessed $28^{\text {th }}$ August 2019.

[4] "NHS England Test Beds Programme: Information Governance learning from Wave," NHS England, September 2018. Report available at https://www.england.nhs.uk/publication/nhs-england-testbeds-programme-information-governance-learning-fromwave-1/, last accessed $28^{\text {th }}$ August 2019.

[5] "2017/18 Annual Report and Accounts," Southern Health and Social Care Trust, March 2018. Report available at http://www.southerntrust.hscni.net/pdf/SHSCT\%20ANNU AL\%20REPORT\%20AND\%20ACCOUNTS\%2031\%20M arch\%202018.pdf, last accessed $28^{\text {th }}$ August 2019.

[6] "Households below average income (HBAI) statistics," Department for Work and Pensions, May 2019. Report available at

https://www.gov.uk/government/collections/householdsbelow-average-income-hbai--2, last accessed $28^{\text {th }}$ August 2019.

[7] "Health state life expectancies by national deprivation deciles, England and Wales Statistical bulletins," Office for National Statistics, March 2017. Report available at https://www.ons.gov.uk/peoplepopulationandcommunity/he althandsocialcare/healthinequalities/bulletins/healthstatelife expectanciesbyindexofmultipledeprivationimd/previousRel eases, last accessed $28^{\text {th }}$ August 2019.

[8] "Healthy life expectancy: Scotland," The Scottish Public Health Observatory, March 2019. Report available at https://www.scotpho.org.uk/population-dynamics/healthylife-expectancy/data/scotland, last accessed $28^{\text {th }}$ August 2019.

[9] "Health Inequalities Regional Report 2016," Department of Health Northern Ireland, Oct 2016. Report available at https://www.health-

ni.gov.uk/sites/default/files/publications/health/hscimsreport-2016.pdf, last accessed $28^{\text {th }}$ August 2019.

[10] "Northern Ireland Waiting Time Statistics: Outpatient Waiting Times Quarter Ending March 2019," Department of Health Northern Ireland, March 2019. Report available at https://www.healthni.gov.uk/sites/default/files/publications/health/hs-niwtsoutpatient-waiting-times-q4-18-19.pdf, last accessed $28^{\text {th }}$ August 2019.

[11] A. Bansal and R. Joshi. "Portable out-of-hospital electrocardiography: A review of current technologies." J Arrhythm, vol. 34, no.2, pp. 129-138, Apr 2018.

[12] "AliveCor Heart Monitor and AliveECG app (Kardia Mobile) for detecting atrial fibrillation," NICE, Aug 2015. Report available at https://www.nice.org.uk/advice/mib35, last accessed $28^{\text {th }}$ August 2019.

[13] "U.S. Smartwatch Sales See Strong Gains, According to New NPD Report," Press release - the NPD Group, Feb 2019. Available at https://www.npd.com/wps/portal/npd/us/news/pressreleases/2019/us-smartwatch-sales-see-strong-gainsaccording-to-new-npd-report/, last accessed $28^{\text {th }}$ August 2019.

[14] "ECG app and irregular heart rhythm notification available today on Apple Watch," Press release - Apple Inc, Mar 2019. Available at https://www.apple.com/uk/newsroom/2019/03/ecg-appand-irregular-rhythm-notification-on-apple-watch- available-today-across-europe-and-hong-kong/, last accessed $28^{\text {th }}$ August 2019.

[15] "User Manual for Kardia" ${ }^{\mathrm{TM}}$ by AliveCor ${ }^{\circledR}$ ", Instruction manual-AliveCor. Nov 2016. Available at https://www.AliveCor.com/previouslabeling/kardia/08LB12.3.pdf, last accessed $28^{\text {th }}$ August 2019.

[16] "Taking an ECG with the ECG app on Apple Watch Series 4", Instruction manual - Apple Inc, Aug 2019. Available at https://support.apple.com/en-gb/HT208955, last accessed $28^{\text {th }}$ August 2019.

[17] "Working in a system that is under pressure", $B M A$, Mar 2018. Report available at https://www.bma.org.uk//media/files/pdfs/collective\%20voice/influence/key\%20neg otiations/nhs\%20pressures/working-system-under-pressurebma-council-report-mar-2018.pdf?la=en, last accessed $28^{\text {th }}$ August 2019.

[18] L. J. Selder, L. Breukel, S. Blok, A.C. Van rossum, I.I. Tulevski and C.P. Allaart. "A mobile one-lead ECG device incorporated in a symptom-driven remote arrhythmia monitoring program. The first 5,982 Hartwacht ECGs." Neth. Heart J., vol. 27, no. 1, pp. 38-45, Jan. 2019.

[19] M. Campbell, "Apple Watch, other wearables increasingly used to manage chronic health conditions, study says", News report - appleinsider, Aug 2018. Available at https://appleinsider.com/articles/18/08/30/apple-watchother-wearables-increasingly-used-to-manage-chronichealth-conditions-study-says, last accessed $28^{\text {th }}$ August 2019.

[20] "Atrial Fibrillation Fact Sheet”, CDC, Aug 2017. Report available

https://www.cdc.gov/dhdsp/data_statistics/fact_sheets/fs_at rial_fibrillation.htm, last accessed $28^{\text {th }}$ August 2019.

[21] "Apple Heart Study demonstrates ability of wearable technology to detect atrial fibrillation", Press release Stanford University School of Medicine, Mar 2019. Available at http://med.stanford.edu/news/allnews/2019/03/apple-heart-study-demonstrates-ability-ofwearable-technology.html, last accessed $28^{\text {th }}$ August 2019.

[22] J.P.J. Halcox, K. Wareham, A. Cardew, et al. "Assessment of Remote Heart Rhythm Sampling Using the AliveCor Heart Monitor to Screen for Atrial Fibrillation: The REHEARSE-AF Study," Circulation, vol. 136, no. 19, pp. 1784-1794, Nov 2017.

[23] G. Boriani, T.V. Glotzer, M. Santini, et al. « Device-detected atrial fibrillation and risk for stroke: an analysis of $>10,000$ patients from the SOS AF project (Stroke preventiOn Strategies based on Atrial Fibrillation information from implanted devices)," Eur. Heart J., vol. 35, no. 8, pp. 50816, Feb 2014

[24] A.Y. Hannun, P. Rajpurkar, M. Haghpanahi, et al, "Cardiologist-level arrhythmia detection and classification in ambulatory electrocardiograms using a deep neural network," Nat. Med. vol. 25, no. 1, pp. 65-69, Jan 2019.

Address for correspondence:

Dr Rob Brisk

Department of cardiology, 68 Lurgan Road, Craigavon Area Hospital, Portadown, Northern Ireland, BT63 5QQ

robbrisk@hotmail.com 